\title{
Research on the Risk of Individual Stock Investment -- Take the Brokerage Sector as an Example
}

\author{
Zheng Ma ${ }^{1,2,3}$, Hongmei Zhang ${ }^{1,2,3}$, Zhiqiang Chen ${ }^{1,2,3}$, Ziyan Wang ${ }^{1,3}$ \\ ${ }^{1}$ Guizhou Institution for Technology Innovation and Entrepreneurship Investment, Guizhou \\ University of Finance and Economics, Guiyang Guizhou 550025, China \\ ${ }^{2}$ Guizhou Institution for Urban Economy and Development, Guizhou University of Finance and \\ Economics, Guiyang Guizhou 550025, China \\ ${ }^{3}$ School of Finance, Guizhou University of Finance and Economics, Guiyang Guizhou 550025,
}

China

\section{个人股票投资的风险研究一一券商板块为例 \\ 马征 ${ }^{1,2,3}$, 张红梅 ${ }^{1,2,3}$, 陈志强 ${ }^{1,2,3}$, 王资燕 1,3 \\ 1 贵州财经大学贵州科技创新创业投资研究院, 贵州贵阳 550025 , 中国 \\ 2 贵州财经大学贵州城镇经济与发展研究院, 贵州贵阳 550025, 中国 \\ 3 贵州财经大学金融学院, 贵州贵阳 550025, 中国}

\begin{abstract}
Today, Invest in the stock market has increasingly perfect continuous development, individual investors has gradually become the main force of stock investment, but due to various constraints, individual investors for face of massive investment information, they cannot identify the valuable investment intelligence information, choice of the value of the investment way are different degrees of defects and individual investors in the face of abnormal fluctuations in the stock market's risk bearing capacity is low. In order to identify individual investors in securities investment risk, this paper selects Shanghai Stock Exchange traded 15 brokerage stocks as a sample, using SPSS factor analysis and cluster analysis methods sample stock ranking and grouping, so as to identify the stock risk and for individual investors in securities investment provide relevant reference.
\end{abstract}

Keywords : Stock Investment Risk; Cluster Analysis; Factor Analysis

\section{摘要}

在股票投资市场日益完善不断发展的今天, 个 人投资者逐渐成为了股票投资的主力军, 但是 个人投资者在面对海量的投资信息时无法甄 别出其中有价值的投资情报信息, 选择的价值 投资方式存在不同程度上的缺陷, 并且个人投 资者在面对股市异常波动时的风险承受能力 偏低。为了识别个人投资者证券投资中的风险, 本文选取上海证券交易所挂牌交易的 15 只券 商股票作为样本, 运用 SPSS 软件中的因子分 析及聚类分析的方法将样本股票排名、分组, 从而识别股票的风险, 进而为个人投资者证券 投资提供相关参考。

关键词：股票投资风险；聚类分析；因子分析 
Risk Analysis and Crisis Response in Big Data Era (RAC-16)

\section{1. 引言}

九十年代以来, 总体上我国的股票市场出现了 两次规模比较大、持续时间比较长的异常波动 状况：第一次是在 2005 年 6 月, 股指从底部 998 点一路殺升至 2007 年 10 月份的 6124.04 点, 最大涨幅达到了 $513.6 \%$, 随后股票指数 在 2008 年 10 月急剧下跌至 1664.93 点; 第二 次是在 2014 年 11 月至 2015 年 6 月。也就是 说, 股票指数在短短半年的时间里, 总涨幅达 到了 $110 \%$ 。然后股票指数于 2015 年 7 月一度 下探至 3373. 54 点, 跌幅达到 35\%; 创业板则 下探至 2304.76 点。作为股票市场中基数较大 的个人投资者一一个人投资者占到中国股市 成交量的 $80 \%$ 至 $90 \%$, 在上述两次的异常波动 中尤其是在下跌阶段损失惨重, 严重套牢。投 资股票的较大不确定因素, 这使得需要合理利 用数据分析的方式来分析数据, 确保能够从泛 滥的数据中提取有效的投资信息以规避投资 风险获得收益。但是, 股市具有变化无常、涨 跌莫测的特点, 加之每个交易日每只股票都会 产生庞大的交易数据和财务数据, 想要在这些 繁琐的数据中获取对个人投资者真实有效的 数据其困难是巨大的。所以, 本文希望通过以 券商股票板块为例, 根据需要充分研究和分析 上市公司的发展前景、历史业绩等相关财务数 据, 在聚类分析和因子分析方法的基础上, 采 用 SPSS. 13 软件分析, 找到一种合理判断上市 公司股票价值，规避个人股票投资风险的方法。

\section{2. 文献综述}

统计方法应用于证券分析的文章已屡见不鲜。 毛哲敏: 在《房地产上市公司资本结构影响因 素实证分析》(2009) 一文中, 以上市公司为 研究对象, 运用主成分分析法, 对我国民营 上市公司的资本结构影响因素进行了实证分 析。李艳在 《房地产上市公司股价影响因素 实证分析》(2012) 一文中选取了房地产上市 公司股票价格指数为因变量, 选择上证综指、 财务业绩、CPI、人民币贷款利率、房地产价 格指数五个因素指标为自变量进行了多元回 归统计建模, 检验结果表明财务业绩对上市 公司股价的影响显著。吕美艳在《房地产上市 公司财务指标的因子分析》 (2011) 一文中,
选取以万科 A、保利地产、招商地产等共计 75 家沪深两市的上市房地产公司, 采用 20 个财 务指标, 对上述房地产上市公司股价波动进 行因子分析, 其结果显示房地产上市公司股价 波动与财务业绩具有正相关的关系。技术分析 大师艾略特在 1938 年根据这一发现他提出了 一套相关的市场分析理论, 精炼出市场的 13 种形态 (Patte - rn ) 或波浪 (Waves), 在市 场上这些型态重复出现, 但是出现的时间间隔 及幅度大小并不一定具有再现性。而后他又发 现了这些呈结构性型态之图形可以连接起来 形成同样型态的更大图形。张祖国: 在《投资 分析》(2014) 一书中指出基本面分析主要从 国家的宏观环境及公司的经营情况几方面来 考察公司的股票价值情况。从以上来看, 以往 的研究主要是对理论方面的研究, 本文试图从 量化的角度来分析证券的投资价值。

\section{3. 数据和指标选取}

\section{1. 数据选取}

本文选择在上海证券交易所挂牌上市的券商 板块的股票进行分析, 排除了 B 股、 $\mathrm{H}$ 股、数 据不可得和有特殊性质的股票后, 进而得到样 本股票 15 只。所以选择券商板块股票进行研 究, 是因为券商的主营业务比较单一, 利润来 源比较集中, 影响收入和利润的因素比较少; 还有绝大部分的个人投资者进行股票投资时 都是通过券商进入股票交易系统进行交易的, 之所以券商板块的股票对个人投资者来讲比 较熟悉, 数据的选取具有可得性, 全面性。数 据来源东方财富股票交易软件, 始数据截止到 2016 年 3 月 31 日的。

\section{2. 指标选取}

目前在评价上市公司基本面状况时, 处于核心 地位的财务数据指标是上市公司的盈利能力、 经营能力、偿债能力和成长能力。由此, 本文 在上述 15 只股票的财务数据中选取 7 个最能 反映这些能力的指标。

（1）盈利能力: 是反映上市公司资金增值的 能力, 盈利能力的大小决定了股票价值的高低, 反映盈利能力的指标有:

(1)净资产收益率=净利润/平均净资产, 反映上 市公司资本的盈利能力, 指上市公司的所有者 
Risk Analysis and Crisis Response in Big Data Era (RAC-16)

通过投入资本在生产经营过程中所取得利润 的能力。该指标是评价上市公司自有资本及其 积累所获得报酬水平的综合指标;

(2)每股收益 $=$ 净利润/总股数, 该比率反映了每 股普股票创造税后利润的能力。

(2) 偿债能力: 是上市公司偿还到期债务 (包 括本息) 的能力, 反映上市公司资产的安全性, 反映偿债能力的指标有:

(3)资产负债率=负债总额/资产总额, 反映了上 市公司的资本结构, 常被用于考察企业的长期 偿债能力。

(4)资产总计 (总资产) $=$ 期末资产总计余额, 反映上市公司实际拥有或者控制的资产。

（3）成长能力: 成长性好的上市公司在总资 产扩张能力, 股本扩张能力, 资产重组方面都 比较强, 反映成长能力的指标有:

(5)营业收入=本年主营业务的总收入。该指标 反映上市公司从本身主要经营的业务中获取 资金的能力以及未来的成长能力。

(6)净利润=本年净利润, 该比率越高表明上市 公司效益越好, 成长能力越强。

(7)营业利润=本年营业收入一本年年初营业成 本, 该比率反映上市公司扩大市场规模的能力

\section{4. 实证分析}

\section{1. 聚类分析概述}

聚类分析就是对抽象对象进行集合分类, 其结 果是由具有某些相似特征的类似对象构成多 个分类。在聚类分析过程中生成的簇是一种数 据对象组合, 同一簇中的对象相似性很高, 而 在不同簇中的对象之间差异很大。计算差异程 度的依据是被描述对象的某种实际属性。聚类 分析方法其实就是把给定的数据集合划分成 不同簇的集合，即在某一空间中规定数据库中 可以获得有限集合或者获得有限取样点集合。 聚类分析的主要目标是把具有相关性的数据 聚集成一类, 使每一类之间的相似性最小, 而 类内数据的相似性最大。
聚类分析目前已经在众多领域中得到运 用, 而且能够在许多应用中结合其他的分析技 术。运用聚类分析方法可以准确识别出稀疏区 域和密集区域, 而且可以在聚类过程中得到整 体的布局方式和数据间固有的联系。聚类类分 析的基本特征：分析方式简单直观。聚类分析 在研究性分析上应用较多, 能从不同的角度理 解分析聚类结果, 最后在不同分析结果中找到 与实际情况最相符的结果。在进行分析的过程 中聚类变量其实就是聚类分析最后得到的解, 增减变量个数, 都会影响最后聚类的结果。

\section{2. 聚类分析}

通过以上对聚类分析的阐述，结合聚类分析的 特点: 事先并不知道根据什么分类, 分成几类。 本文通过 SPSS 软件对样本数据进行系统聚类 分析, 在聚类分析中, 首先对数据进行无量钢 化处理, 其次进行标准化处理, 其次用 SPSS 软件中的分析中选择分类按钮对数据进行分 类。标准化处理结果如表 1 所示:

表 1 凝聚顺序表

\begin{tabular}{|l|l|l|l|l|l|l|}
\hline $\begin{array}{l}\text { 编 } \\
\text { 号 }\end{array}$ & $\begin{array}{l}\text { 簇 } \\
\text { 集 } \\
1\end{array}$ & $\begin{array}{l}\text { 簇 } \\
\text { 集 } \\
2\end{array}$ & $\begin{array}{l}\text { 系 } \\
\text { 数 }\end{array}$ & $\begin{array}{l}\text { 簇 } \\
\text { 集 } \\
1\end{array}$ & $\begin{array}{l}\text { 下 } \\
\text { 集 } \\
2\end{array}$ & $\begin{array}{l}\text { 阶 } \\
\text { 段 }\end{array}$ \\
\hline 1 & 2 & 10 & .211 & 0 & 0 & 3 \\
\hline 2 & 3 & 9 & .418 & 0 & 0 & 3 \\
\hline 3 & 2 & 3 & .575 & 1 & 2 & 6 \\
\hline 4 & 11 & 12 & .847 & 0 & 0 & 6 \\
\hline 5 & 7 & 15 & .952 & 0 & 0 & 9 \\
\hline 6 & 2 & 11 & 1.060 & 3 & 4 & 10 \\
\hline 7 & 1 & 4 & 1.105 & 0 & 0 & 12 \\
\hline 8 & 5 & 6 & 1.279 & 0 & 0 & 11 \\
\hline 9 & 7 & 8 & 1.455 & 5 & 0 & 10 \\
\hline 10 & 2 & 7 & 1.826 & 6 & 9 & 11 \\
\hline 11 & 2 & 5 & 5.203 & 10 & 8 & 13 \\
\hline 12 & 1 & 13 & 9.981 & 7 & 0 & 13 \\
\hline 13 & 1 & 2 & 21.843 & 12 & 11 & 14 \\
\hline 14 & 1 & 14 & 41.727 & 13 & & 0 \\
\hline
\end{tabular}

表 1 输出结果第一行数据的含义是在聚 类分析的第一步中, 2 号个案与 10 号个案聚 成一类, 样本离差平方和是 0.211 , 这个小类 将会在在聚类分析的第 3 步用到。同理，第 3 


\section{Risk Analysis and Crisis Response in Big Data Era (RAC-16)}

行数据的含义是在聚类分析的第 3 步中, 3 号 个案与第一步聚成的小类又聚成另外一小类, 他们的离差平方和是 0.575 , 这个小类将在聚 类分析的第 6 步用到。可见, 经过 14 步聚类 过程, 15 个个案最后聚成了一大类。

根据上述聚类分析的方法与过程, 通过 SPSS 软件可以将 15 个个案根据离差平方和分为 4 类, 具体的分类情况如表 2 所示。

表 2 分类簇集表

\begin{tabular}{|l|l|l|l|}
\hline 1:中信证券 & 1 & 9 :兴业证券 & 2 \\
\hline 2:国金证券 & 2 & 10 :东吴证券 & 2 \\
\hline 3:西南证券 & 2 & 11 :东兴证券 & 2 \\
\hline 4:海通证券 & 1 & 12 :东方证券 & 2 \\
\hline 5:招商证券 & 2 & 13 :国泰君安 & 3 \\
\hline 6:华泰证券 & 2 & $14:$ 安信信托 & 4 \\
\hline 7:光大证券 & 2 & $15:$ 国投安信 & 2 \\
\hline 8:方正证券 & 2 & & \\
\hline
\end{tabular}

由表2可以看出, 第一类上市公司包含国 金证券、方正证券、东吴证券、西南证券、兴 业证券、东兴证券、东方证券、光大证券、国 投安信, 这一类公司业绩一般, 表现平平, 是 市场中的主体部分, 占据市场主体; 第二类公 司对应的股票有招商证券、华泰证券, 这一类 公式比第一类表现稍好一些; 第三类公司包含 海通证券、中信证券、国泰君安, 这一类股票 是市场上表现较好的股票, 风险相对较低; 第 四类上市公司包含安信信托, 这一类股票是在 市场上表现较差的一类股票。

\section{5. 因子分析}

虽然在以上部分对 15 只股票进行了分类, 但 是在实际投资过程中, 只是进行分类是不够的, 比较片面。为了能够进一步了解是什么因素造 成了股票之间的不同市场表现, 下面运用因子 分析, 选取 7 个常用财务指标, 也是投资者很 容易获取的几个指标。从中找出具有主导影响 力因素。

\section{1. 因子分析概述}

因子分析模型的建立步骤大致为:
第一, 建立指标体系, 构成原始矩阵, 保证全 部指标同向化对样本数据进行标准化处理得 到标准化矩阵, 计算变量的简单相关系数矩阵。 第二, 解特征方程 $|\mathrm{R}-\lambda \mathrm{E}|=0$, 计算相关矩阵 的特征值 $\lambda$, 若 $\lambda 1 \geqslant \lambda 2 \geqslant \cdots \lambda p$, 以 $\lambda p \geqslant 1$ 为 标准确定公共因子个数 $\mathrm{P}$ 。

第三, 计算初始因子载荷矩阵和公共因子方差, 用正交或斜交旋转的方法求得正交或斜交因 子载荷矩阵; 根据正交或斜交因子载荷矩阵相 关系数绝对值, 确定并命名公共因子。

最后, 计算公因子得分和最后得分。

\section{2. 因子分析}

对原始数据进行 KMO 和 Bartlett 检验, 其结果 如表 3 所示:

表 3 KMO 和 Bartlett 检验

\begin{tabular}{|lc|l|}
\hline Kaiser-Meyer-Olkin:取样足够度 & .679 \\
Bartlett 的球形检近似卡方 & 153.188 \\
验 & df & 21 \\
& 显著性 & .000 \\
\hline
\end{tabular}

其中 $\mathrm{KMO}$ 值为 0.679 , 表示比较适合进行 因子分析; Bartlett 的球形检验的原假设为相 关系数矩阵为单位阵, 结果显示显著性水平为 0.000 , 小于显著性水平 0.05 , 因此拒绝原假 设, 说明变量之间存在相关关系, 适合做因子 分析。

表 4 因子贡献率

\begin{tabular}{|c|c|c|c|c|c|c|c|c|c|}
\hline \multirow{3}{*}{ 成 } & \multicolumn{3}{|c|}{ 初始特征值 } & \multicolumn{3}{|c|}{ 提取平方和载入 } & \multicolumn{3}{|c|}{ 旋转平方和载入 } \\
\hline & 合 & 差 & & 总 & 差 & 累 & & & 累 \\
\hline & 计 & 的\% & 累计\% & 计 & 的\% & 计\% & 总计 & 差的 & 计\% \\
\hline & 3.93 & 56.23 & 56.237 & 3.93 & 56.23 & 56.23 & 3.93 & 56.19 & 56.19 \\
\hline 2 & 2.59 & 37.10 & 93.338 & 2.59 & 37.10 & 93.33 & 2.60 & 37.14 & 93.33 \\
\hline 3 & .260 & 3.712 & 97.050 & & & & & & \\
\hline 4 & .130 & 1.862 & 98.912 & & & & & & \\
\hline 5 & .055 & .788 & 99.700 & & & & & & \\
\hline 6 & .019 & .272 & 99.972 & & & & & & \\
\hline 7 & .002 & .028 & 100.00 & & & & & & \\
\hline
\end{tabular}


Risk Analysis and Crisis Response in Big Data Era (RAC-16)

表 4 给出了因子贡献率的结果。左侧部分 为初始特征值, 中间为提取主因子结果, 右为 旋转后的主因子结果。其中前两个因子的特征 值大于 1 , 并且前两个因子的特征值总和占总 特征值的 $98.912 \%$, 因此, 提取前两个子作为 主因子。

表 5 旋转因子负荷矩阵

\begin{tabular}{|l|l|l|}
\hline \multirow{2}{*}{} & \multicolumn{2}{|l|}{ 元件 } \\
\cline { 2 - 3 } & 1 & 2 \\
\hline 每股收益 & .433 & .840 \\
净资产收益率 (\%) & -.157 & .973 \\
营业收入 (亿) & .969 & .036 \\
营业利润（亿元） & .971 & .098 \\
净利润（亿元） & .991 & .062 \\
总资产（亿元） & .909 &. .254 \\
资产负债比率（\%) & .180 & .932 \\
\hline
\end{tabular}

表 5 的二、三列分别是两个征值所对应的 特征向量。可以看到表中的七指标: 营业收入、 营业利润、净利润以及总资产在第一公因子上 具有正向负荷, 说明可以将第一个主因子命名 为“盈利因子”, 主要反映上市公司获取收入, 赢的利润的状况。每股收益、净资产收益率在 第二公因子上具有较大的正向负荷, 说明可以 将第二个公因子命名为 “收益因子”, 主要反 映上市功能是公司股东获得收益的状况。

表 6 成分得分系数矩阵

\begin{tabular}{|l|l|l|}
\hline \multirow{2}{*}{} & \multicolumn{2}{|l|}{ 成分 } \\
\cline { 2 - 3 } & 1 & 2 \\
\hline 每股收益 & 115 & .326 \\
净资产收益率 (\%) & .034 & .373 \\
营业收入 (亿) & .246 &. .008 \\
营业利润 (亿元) & .248 & .044 \\
净利润 (亿元) & .252 & .030 \\
总资产 (亿元) & .230 & .092 \\
资产负债比率 (\%) & .040 & .358 \\
\hline
\end{tabular}

由表 6 可以得到:

$\mathrm{F} 1=0.115 \mathrm{zscore}($ 每股收益 $)+0.246 z s c o r e($ 营业 收入 $)+0.248 z s c o r e($ 营业利润 $)+0.252$ zscore (净利润) +0.230 zscore (总资产) $+0.040 z s c o r e$
(资产负债率) - 0.034zscore（净资产收益率） $\mathrm{F} 2=0.326 z s c o r e($ 每股收益 $)+0.373$ zscore $($ 净资 产收益率) $+0.044 \mathrm{zscore}$ (营业利 润 $)+0.030$ zscore (净利润) -0.008 zscore (营业 收入） -0.092 zscore (总资产) -0.358 (资产负 债率)

标准化之后的数据代入上述方程就可以 计算出每一只股票的各个因子的评价得分, 然 后以各因子方差贡献率占两个个因子总方差 贡献率比重作为权重进行加权汇总, 得出每只 股票的综合得分，根据综合得分可以获得上市 公司的排名，如表 7:

\begin{tabular}{|l|l|l|}
\multicolumn{3}{|c|}{ 表 7 综合排名 } \\
\hline 排名 & 名称 & 综合得分 \\
\hline 1 & 中信证券 & 4.7100 \\
\hline 2 & 海通证券 & 4.5321 \\
\hline 3 & 国泰君安 & 4.0322 \\
\hline 4 & 招商证券 & 3.9612 \\
\hline 5 & 光大证券 & 3.5543 \\
\hline 6 & 西南证券 & 3.2100 \\
\hline 7 & 华泰证券 & 3.002 \\
\hline 8 & 兴业证券 & 2.9623 \\
\hline 9 & 东方证券 & 2.9510 \\
\hline 10 & 方正证券 & 2.6336 \\
\hline 11 & 东吴证券 & 2.4897 \\
\hline 12 & 东兴证券 & 2.0156 \\
\hline 13 & 国投安信 & 1.9991 \\
\hline 14 & 国金证券 & 1.8752 \\
\hline 15 & 安信信托 & 1.0211 \\
\hline
\end{tabular}

通过综合实力得分可以得出的结论: 第三 类股票中中信证券、海通证券和国泰君安综合 实力得分最高, 进行股票投资的时候可以买入, 风险相对较低; 第二类股票中招商证券和华泰 证券得分比较高, 代表这两只股票在买入时需 加以考虑分析其收益的情况, 风险相对第三类 较高一些; 第一类股票的综合实力得分排名占 据主体位置，表明国金证券、方正证券、东吴 证券、西南证券、兴业证券、东兴证券、东方 证券、光大证券和国投安信在市场中的表现一 般, 风险比较高, 在选择购买时多加权衡; 第 四类股票, 安信信托得分最低, 表明这只股票 在市场当中的表现不好, 再进行投资的时候尽 量规避。 
Risk Analysis and Crisis Response in Big Data Era (RAC-16)

\section{6. 总结}

基于 SPSS 软件的因子分析的方法可以有效地 减少在个人投资上市公司股票时需要考虑的 指标数目, 聚类分析可以清晰的将具有不同因 子特征的上市公司分类, 找出适合个人投资者 投资风险承受的股票。这两类方法的优点在于:

(1) 可以浓缩上市公司公开的财务指标, 用很少的因子代替繁杂的指标种类, 使个人投 资者对上市公司有一个简明、清晰的认识:

（2）个人投资者可以清晰的看到每个因 子下每只股票的得分排名情况以及综合得分 排名情况, 便于比较上市公司在经营管理能力 等各方面的优劣;

（3）投资者可以找到适宜达到自己投资 决策的目标类型的股票来权衡自己的投资风 险。

\section{7. 参考文献}

[1]何晓群. 多元统计分析. 北京: 中国人民大 学出版社, 2012.

[2]范坤, 冯长焕. 因子分析中指标数据如何正
确预处理. 财会月刊: $2013(003): 85-88$.

[3] 曹裕, 陈晓红, 王傅强. 我国上市公司生命 周期划分方法实证比较研究. 系统管理学报, 2010 (3) : 313-322.

[4] 陈琦. 聚类分析和判别分析在股票投资中 的应用. 中国市场， 2011，26:69-72.

[5]邓秀勤. 聚类分析在股票市场板块分析中 的应用. 数理统计与管理， 1999 . 5(18): (1-4).

[6]李德荣, 何莉敏, 李玉. 聚类分析和因子 分析在股票投资中的应用. 内蒙古统计, 2011，01:29-31.

[7]李艳. 房地产上市公司股价影响因素实证 分析. 特区经济，2012，09:84-86.

[8] 吕美艳. 房地产上市公司财务指标的因子 分析. 现代商业, 2011，36:209.

[9]毛哲敏. 房地产上市公司资本结构影响因 素实证分析. 商场现代化, 2009, 18:80-81.

[10]J.K Yu, Z.F. Zhou. The errors estimate of the multistage combined investment risk assessment. Journal of Risk Analysis and Crisis Response, 2011 (1): 106-109. 